\title{
DOES CONTEXTUALISM HINGE ON A METHODOLOGICAL DISPUTE?
}

\author{
Jie Gao, Mikkel Gerken and Stephen B. Ryan
}

\section{Introduction}

Epistemic contextualism (henceforth: contextualism) is, roughly, the semantic thesis that the truthconditional contribution of "knows" vary with variations in the context of utterance. Contextualism has been surrounded by methodological disputes as long as it has existed. In fact, a large number of the debates that characterize contemporary meta-epistemology resemble the methodological disputes over contextualism. We think that this is no mere accident. Rather, the nature of and motivation for contextualism naturally raise methodological questions. What is the proper relationship between epistemology and philosophy of language? What is the role of intuitive judgments in epistemological theorizing? What is the proper response when our epistemological theories are incongruous with our folk epistemology?

In this chapter, we aim to simultaneously provide an overview of some of the methodological debates surrounding contextualism and consider whether they are, in effect, based on an underlying methodological dispute. We proceed as follows: In Section 2, we articulate two questions that our discussion will address. In Section 3, we consider case-based motivations of contextualism and DeRose's 'methodology of the straightforward.' In Section 4, we consider the methodology that consists in modeling a contextualist semantics of "knows" on other contextsensitive linguistic phenomena. In Section 5, we consider attempts to motivate contextualism by appeal to imagined conceptual genealogies or functional roles. In Section 6, we discuss the challenges from experimental philosophy from a methodological perspective. In Section 7, we conclude by revisiting the question as to whether the debates over the case for contextualism are based on a methodological dispute.

\section{Contextualism and methodological disputes}

As mentioned, contextualism has since its earliest developments been surrounded by disputes of a methodological character. For example, its attempt to 'dissolve' skeptical paradoxes was motivated by meta-epistemological considerations such as considerations about the aims of epistemology (Cohen 1999, 2005; DeRose 1995, 1999, 2004; Lewis 1996). However, the contextualist approach was countered with meta-epistemological criticism (Schiffer 1996, 2004). For example, critics questioned whether a semantic thesis is apt to solve epistemological problems (Sosa 2000; Kornblith 2000). 
Naturally, contextualists have responded to these methodologically oriented criticisms. But very often the methodological and the substantive issues have been addressed in unison. This raises the question as to whether contextualists 'have a distinctive methodology' or more specifically whether there are any methodological doctrines that underlie the dispute between contextualists and their opponents? This broad quandary is reflected in our title. But to begin to address this grand issue, we will articulate it a manner that is a bit more conspicuous (and admittedly less grand) as two distinct but interrelated meta-methodological questions.

Q1: Is there a distinctive methodological doctrine or set of methodological doctrines that is centrally invoked by all epistemic contextualists?

Q2: Does the substantive dispute concerning the truth of contextualism depend on underlying methodological disputes?

Q1 and Q2 are logically independent. Some doctrine could be common to all contextualists without explaining the dispute between contextualists and their opponents-perhaps because the doctrine is also accepted by the majority of the opponents. On the other hand, it might be that whereas contextualism is motivated by various distinct methodologies, opponents to contextualism are in each case in disagreement with the methodology in question.

By structuring the discussion around these two meta-methodological questions, we hope to advance the debates by gaining some clarity on the various aspects of contextualist methodology. We also seek to advance the debate by providing preliminary and qualified answers to the two questions. Roughly, we will answer Q1 by a qualified "no" and Q2 by a qualified "yes." There is no single methodology or set of methodological doctrines that is distinctive of contextualism in the sense that all contextualists centrally invoke it. Nevertheless, we will suggest that each of the disputes between contextualists and invariantists tend to be characterized by considerable methodological disputes about what epistemology is or how to motivate an epistemological theory.

Of course, these are complex and preliminary answers. One reason why the questions do not admit of simple and conclusive answers is the noted one that both contextualists and their opponents tend to discuss methodological considerations in tandem with first-order substantive epistemological questions. So, while many contextualist writings contain meditations on matters methodological, the key methodological commitments of contextualists must be articulated by juxtaposing these remarks with critical reflections on the contextualists' practice. That is, the contextualist methodologies may to some extent be arrived at by 'backward engineering' from considerations on how contextualists go about arguing for the view, responding to criticism and so forth.

In consequence, we will consider three modes of motivation in turn: The method of cases (Section 3), the appeal to linguistic analogies (Section 4) and the appeal to conceptual analogies and functional roles (Section 5). We will then consider the methodological debates arising from experimental philosophy (Section 6) and conclude by answering Q1 and Q2 (Section 7). An advantage of this modus operandi is that it will also serve as an overview of the dominant methodological approaches of various contextualists.

\section{The method of cases and the methodology of the straightforward}

The most prominent way of motivating contextualism is by appeal to case pairs with the following structure: Every factor that epistemologists have traditionally taken to be a partial determiner of whether knowledge ascribing sentences are true is held fixed, but aspects of the speaker's conversational context vary between the cases (DeRose 1995, 2009; Cohen 1999). These factors may involve what is at stake, or what error-possibilities are salient, or both. For example, DeRose's bank cases involve the case LOW in which there is a first-person knowledge ascription in a conversational context where little is at stake and which does not mention any alternative to the 
complement clause of the knowledge ascription. This is contrasted with a case, HIGH, in which there is a first-person knowledge denial in a high-stakes case with a conversationally salient alternative (DeRose 1995, 2009: 1ff).

DeRose claims that ordinary speakers deem the knowledge ascription true in LOW and that they also deem the knowledge denial true in HIGH. He claims that "where the contextualist's cases are well chosen, those are fairly strong intuitions about the cases, at least where each case is considered individually" (DeRose 2005, 2009: 49). Thus, the motivation by cases involves appealing to our intuitive judgments about knowledge ascriptions in isolation and to assumptions about "how speakers in fact, and with propriety, use the claims in question" (DeRose 2009: 50).

This 'methodology of the straightforward', as we may call it, takes very seriously the simple positive and negative claims speakers make utilizing the piece of language being studied, and puts a very high priority on making those natural and appropriate straightforward uses come out true, at least when that use is not based on some false belief the speaker has about some underlying matter of fact. Relatively little emphasis is then put on somewhat more complex matters, like what metalinguistic claims speakers will make and how they tend to judge how the content of one claim compares with another (e.g. whether one claim contradicts another.)

(DeRose 2009: 153)

DeRose is cautious to mention that his attraction to the methodology of the straightforward requires that "its favoring of simple data is not taken too far" (DeRose 2009: 153). Yet the methodology of the straightforward may be criticized. For example, it may be challenged on empirical grounds whether ordinary speakers in fact speak in this manner. We will consider this line of criticism in Section 6 below. However, the methodology of the straightforward may also be criticized from a more reflective standpoint. For example, it might be questioned whether it is reasonable to consider the positive and negative knowledge ascriptions in isolation. In many cases, comparative judgments allow us to see flaws in our initial judgments. The idea that it is methodologically more sound to reflect on comparative judgments than to rely on intuitive judgments in isolation is related to one of the most tenacious substantive problems for contextualism—namely, the problem of disagreement: If Ali in HIGH utters 'S knows that $p$ ' and Adam in HIGH utters 'S does not know that $p$ ' they appear to disagree and, indeed, to contradict each other (MacFarlane 2014). Importantly, this appearance does not appear to go away on reflection, as one would expect if it were simply due to the two knowledge ascriptions expressing different propositions (Rysiew 2001. See DeRose 2009 for a response). But critics argue that it is methodologically more sound to rely on reflective judgments about both utterances than on intuitive judgments about the utterances in isolation (Nagel 2010, Gerken 2012, Ms Ch. 3).

Consequently, non-skeptical invariantists attempt to cast doubt on the reliability of the intuitive judgment that the knowledge denial is true. One strategy consists in arguing that the utterance in HIGH is false but felicitous in virtue of pragmatically conveying something true or appropriate (Dretske 1986; Rysiew 2001; Brown 2006; Bach 2008, 2010; Hazlett 2009; Pritchard 2010). Another response, that reflects the idea that we should rely on reflective comparative judgments rather than on intuitive isolated judgments, consists in postulating that the intuitive judgments in HIGH are false due to a cognitive bias (Nagel 2008, 2010; Gerken 2012, 2013; Turri 2015).

We will not here canvass the legitimacy of these strategies. What we want to highlight is how they reflect an important methodological alternative to the methodology of the straightforward. Critics of contextualism tend to argue that contextualists' reliance on intuitive judgments about cases in isolation is methodologically suspect because more reflective comparative judgments are a better basis for epistemological theorizing. Contextualists may respond that such an approach may just amount to presupposing non-skeptical invariantism and diverge from how "knows" is actually used. To this, invariantists may respond that our ordinary talk reflects the pragmatic or 
psychological effects that they postulate. So, the methodological discussion and substantive arguments are often interwoven. Thus, the methodology of the straightforward and the invariantist alternative may reasonably be said to underlie the substantive debates about the plausibility of contextualism.

However, it is important to recognize that contextualists do not rely exclusively on the methodology of the straightforward. For example, DeRose, Lewis, Cohen, and Blome-Tillmann all argue that it is a theoretical advantage of contextualism that it can (dis)solve skeptical problems (DeRose 1995, 2009; Lewis 1996; Cohen 1999; Blome-Tillmann 2009, 2014). Nevertheless, we think that the methodology of the straightforward is primary in two important senses. First, contextualism is a semantic thesis about the truth conditions of "knows" and in consequence it must be given a linguistic (use-based) motivation. Second, since we do not want to (dis)solve skeptical paradoxes by a false semantic theory, the putative ability to resolve skeptical paradoxes is secondary to independently motivating the semantic theory.

Finally, we want to acknowledge approaches to LOW-HIGH cases that rely less on intuitive judgments. Several contextualists argue that contextualism provides the best answer to a question raised by commitment to non-skeptical fallibilism (Lewis 1996; Cohen 1999; Blome-Tillmann 2014. See Brown 2013 for discussion): How good an epistemic position must $S$ be in for it to be true to assert that $S$ knows that $p$ ? The contextualist argues that there is a reason why invariantists have failed to answer this question. The reason, according to contextualism, is that the required epistemic position depends on the conversational context. Given this answer, reflection on the LOW-HIGH cases may be seen as augmenting this theoretical move rather than as providing selfstanding 'data' that a theory must account for. So, while the methodology of the straightforward remains a prominent contextualist methodology underlying the appeal to LOW-HIGH case pairs, it may not be required in appeals to such cases in motivating contextualism. In fact, some contextualists do not seem to rely on it. If the methodology of the straightforward is merely prominent but not always relied upon, we should answer Q1 in the negative. On this note, let's consider a prima facie distinct methodological approach.

\section{Linguistic analogies}

An important line of motivation for contextualism has gone via linguistic analogies to other areas of language. A number of linguistic analogs have been suggested but here we will only briskly discuss two prominent candidates: gradable adjectives and universal domain restriction (See Cohen 1999; DeRose 2009 for the former and Lewis 1996 for the latter).

Cohen presents the analogy with gradable adjectives as follows:

Many, if not most, predicates in natural language are such that the truth-value of sentences containing them depends on contextually determined standards, e.g. 'flat', 'bald', 'rich', 'happy', 'sad'.... These are all predicates that can be satisfied to varying degrees and that can also be satisfied simpliciter. So, e.g., we can talk about one surface being flatter than another and we can talk about a surface being flat simpliciter. For predicates of this kind, context will determine the degree to which the predicate must be satisfied in order for the predicate to apply simpliciter. So the context will determine how flat a surface must be in order to be flat.

(Cohen, 1999: 60)

Thus, Cohen and other contextualists suggest that gradable adjectives such as "flat" or "rich" provide a semantic model for "knows". Just as conversational context determines how much money it takes for the sentence "S is rich" to be true, conversational context is said to partly determine how much justification it takes for the sentence "S knows that $p$ " to be true. If the analogy with gradable adjectives holds, the fact that a class of terms exhibit a semantic structure 
similar to that postulated for "knows" may help to embed contextualism in existing semantic frameworks. This in turn may serve as a potential response to the objection that the contextualist semantics for "knows" is an epistemological invention with no parallels in natural language.

Quantifier domain restriction provides another candidate linguistic analogy for "knows." This approach most naturally takes place in a relevant alternatives framework according to which S knows that $p$ only if $\mathrm{S}$ can rule out every relevant alternative to $p$. The term "every" is context-sensitive insofar as the domain of its application is partly determined by conversational context. When Lewis says "all the glasses are empty" he refers to all the glasses at the table, not all the glasses in the bar and much less all the glasses in the world (Lewis 1996). By analogy, the term "knows" is said to be context-sensitive insofar as the size of the set of alternative possibilities that is relevant is partly determined by conversational context. In Lewis' memorable phrase: "S knows that $p$ iff S's evidence eliminates every possibility in which not- $p$ - Psst! - except for those possibilities that we are properly ignoring" (Lewis 1996: 554; emphasis in original. See Blome-Tillmann 2009, 2012, 2014; Ichikawa 2011 for developments).

The opposition takes several forms. From a methodological perspective, one brand of invariantist opposition to contextualism 'plays along' and adopts the methodological assumptions underlying the appeal to linguistic analogies. Such anti-contextualists seek to argue that there are important asymmetries between "knows" and the linguistic models that contextualists invoke. Stanley - an interest-relative invariantist—argues that "knows" is not gradable (Stanley 2005. See Blome-Tillmann 2014 for a response). Similarly, some opponents of contextualism argue that there are linguistic differences between the behavior of "knows" and other forms of quantified domain restriction. For example, Stanley argues that the standards for "knows" are more easily raised than lowered whereas the domain restriction on many quantifiers does not exhibit a similar asymmetry (Stanley 2005: 65). But since those are arguments postulating linguistic disanalogies, they are not at odds with the basic methodology of considering linguistic analogies. An example of noninvariantist who is also seeking to beat contextualists on their own linguistic turf is MacFarlane, who serves up a bowl of linguistic data to argue that relativism is superior to contextualism (MacFarlane 2014). We take it that the opponents of contextualism who engage in disputes over the linguistic data accept that such data is methodologically appropriate for epistemological theorizing.

Another line of opposition, however, is characterized by resistance to the idea that linguistic analogies are methodologically appropriate for epistemological theorizing. Sometimes this line of resistance is articulated as the charge that contextualists are changing the topic or, in Kornblith's gloss, "evading epistemology" (Kornblith 2000). One version of this response does not object to contextualism or its motivation. Rather, it consists in holding that an account of the truthconditions of the term "knows" does not tell us anything of epistemological substance (for a contextualist response to such worries see DeRose 2009).

A related complaint pertains to the contextualist (dis)solution of skeptical paradoxes (Conee 2005; Feldman 1999, 2001, 2004; Klein 2000, 2015; Kornblith 2000; Sosa 2000, 2004; Bach 2010). According to this complaint, the contextualist solution is too concessive insofar as we want an account of how "S knows that $p$ " is true in a skeptical context. Contextualists are seen as shying away from the desired solution to the skeptical paradox that consists in indicating which premise is false in favor of a semantic dissolution. Of course, such complaints have been met with responses by contextualists - most elegantly by Lewis, who argues that this sort of complaint is methodologically misguided because it presupposes that the skeptical paradox has a solution that may be asserted (Lewis 1996; see Blome-Tillmann 2014 for a development that is designed to be less concessive to skepticism).

How do these considerations bear on our two methodological questions? With regard to Q1, the question as to whether there is a specific methodology that is centrally invoked by all contextualists, the considerations suggest that it should be answered in the negative. After all, the arguments from linguistic analogies are at least independent from the arguments from cases and 
vice versa. With regard to $\mathrm{Q} 2$, the answer is less clear. On the one hand, one strand of resistance to arguments from linguistic analogies is overtly methodological insofar as it consists in holding that such arguments are irrelevant for the purpose of epistemological theorizing. On the other hand, another strand of opposition appears to accept the methodology but seeks to beat contextualists on their own terms. However, this latter group may differ methodologically in how they assess the linguistic evidence. For example, contextualists may regard "knows" as a species of a gradable term with some distinctive features whereas the opponents take these features to suggest that "knows" is not a gradable term at all. So, the cases of linguistic analogy are to a significant extent shaped and influenced by underlying methodological disagreements.

\section{Conceptual genealogies and functional roles}

Another way of motivating contextualism appeals assumptions about the social functional roles of "knows" in order to reach conclusions about its semantics. This broad approach is often although not invariably - inspired by Craig.

Craig pursues what he calls a conceptual synthesis, which differs from a conceptual analysis in that it does not pursue necessary and sufficient conditions for the application of the concept of knowledge (Craig 1986, 1990, 2007). Rather, a conceptual synthesis characterizes the concept of knowledge via 'practical explication' of the social functions of knowledge ascriptions. Craig does so via a genealogical methodology which he characterizes as follows:

We take some prima facie plausible hypothesis about what the concept of knowledge does for us, what its role in our life might be, and then ask what a concept having that role would be like, what conditions would govern its application.

(Craig 1990: 2)

According to Craig, the conceptual synthesis is genealogical and has two stages. The first stage accounts for how an ancestor to the concept of knowledge came about in what Craig labels an "epistemic state of nature" (Craig 1990). Kusch labels this precursor the concept of protoknowledge (Kusch 2009, 2011). The epistemic state of nature is an imaginary early, social community of language-using humans who cooperate and therefore need to depend on each other as informants. Hence, these humans need a concept to identify reliable informants and Craig suggests that the concept of protoknowledge serves this function (Craig 1990: 11). According to Craig the features of a good informant are the following:

(1) He should be accessible to me here and now.

(2) He should be recognizable by me as someone likely to be right about $p$.

(3) He should be as likely to be right about $p$ as my concerns require.

(4) Channels of communication between me and him should be open.

These features are highly contextualized. But they characterize a concept that is very different from our present concept of knowledge. Consequently, the second stage of Craig's genealogy postulates a "process of objectivisation" during which the contextual aspects of the precursor concept are replaced with objective ones. The end-result is our concept of knowledge. For example, the requirement, (3), that the protoknower should be as likely to be right about $p$ as the inquirer's concerns require is said to be "objectivized away." Indeed it is replaced with a reliability requirement according to which a knower must be: “...someone with a very high degree of reliability, someone who is very likely to be right-for he must be acceptable even to a very demanding inquirer" (Craig 1990: 91). 
Contemporary theorists adopt select ideas of Craig's proposal to motivate varieties of contextualism (Greco 2007, 2012; Hannon 2013, 2015; Henderson 2009, 2011; McKenna 2013, 2014). It should be noted, however, that many of these theorists part ways with Craig's specific genealogical approach in favor of a broader appeal to the functional roles of knowledge ascriptions. However, the key idea that the function of knowledge ascriptions serve to flag reliable informants continues to figure centrally.

For example, Henderson's "gate-keeping contextualism" appeals to Craig's idea that knowledge ascriptions serve the central function of gate-keeping sources in a social epistemic community (Henderson 2009, 2011). Crucially, Henderson assumes that the semantics constitutive of the concept turns on this function:

To say that a concept arose with "a constitutive eye to" the demands of successful practice, and that what makes for success there is central to the "core conception" of the concept, is to say that the semantics constitutive of the concept turn on what makes for such success...

(Henderson 2011: 86)

Given such an assumption and the further assumption that it is a contextual matter whether it is reasonable to certify $\mathrm{S}$ as a good source of information, contextualism may be motivated by genealogical considerations. Various theorists have pursued variations of this line of reasoning. For example, Greco argues that it is "the relevant practical reasoning environment" which determines the context in question and therefore the context may be that of the attributor, the subject, or someone else (Greco 2008: 433). Henderson emphasizes that since a potential source is assessed for general purposes, there is some stability to the contextual variance (Henderson 2011). Likewise, Hannon seeks to "stabilize" the content of knowledge ascriptions so as to allow for a restricted contextual variance with practical factors (Hannon 2015). Since space dictates that we set aside differences between the proponents of this broad strategy, we will restrict our more critical assessment to Craig's approach (but see Gerken 2015, Ms).

The genealogical approach is often rejected on the grounds that Craig's genealogy and imaginary "epistemic state of nature" are overly speculative and empirically unconstrained (Gelfert 2011, Kelp 2011, Kornblith 2011, Beebe 2012). This way of objecting to Craig's methodology is especially damaging to appeals to it in motivating contextualism. After all, contextualism purports to be a semantics of our term "knowledge." So, if the genealogy is at odds with the best empirical theories of conceptual development, why think it bears on our concept of knowledge and, by extension, on the semantics of "knowledge"?

This line of objection questions the genealogical methodology and its capacity to motivate contextualism. As such, it exemplifies how the debate between contextualists and invariantists reflects a debate about philosophical methodology. This suggests an affirmative answer to Q2, the question as to whether the dispute between contextualists and invariantists hinges on a methodological dispute. On the other hand, opponents to contextualism do not have to reject the genealogical method. Indeed, invariantists may challenge the genealogical motivation of contextualism on Craigian grounds. For example, it may be noted that Craig only claims that the ancestor concept is heavily contextualized, not that our present day objectivized concept is (Gerken $M s)$. If so, invariantists may accept Craig's genealogical considerations by arguing that they do not on reflection motivate contextualism. Thus, invariantist criticism is, at least in principle, compatible with genealogical methodology. So, on balance the debates over genealogical motivations of contextualism suggest a more guarded answer to Q2: while the dispute between contextualists and invariantists often reflects an underlying methodological dispute, it need not do so.

With regard to Q1, the question as to whether contextualism has a distinctive methodology or set of principles in common, the discussion suggests a negative answer. After all, Craig's conceptual synthesis and genealogical method is a highly unorthodox and distinctive alternative to 
existing methodologies. So, since the genealogical method is a novel way to motivate contextualism, contextualists are not committed to a particular methodology. Moreover, the fact that contextualists often appeal to functional role without invoking genealogies provides evidence for a plurality of contextualist methods.

\section{The challenge from experimental philosophy}

As discussed in Section 3, a prominent way of motivating contextualism includes an empirical claim concerning ordinary linguistic practice. As DeRose puts it: “...what ordinary speakers will count as 'knowledge' in some non-philosophical contexts they will deny is such in others" (DeRose 2009: 47). One type of challenge to contextualism deploys experimental techniques to scrutinize this specific claim. Another type of challenge targets more general reliance on intuitive judgments concerning cases in support of this empirical claim. We will consider these challenges in reverse order.

Part of the support for the contextualist's empirical claim stems from intuitive judgments about cases. Some experimental philosophers challenge this line of support by arguing that any epistemically significant reliance on intuitive judgments is illegitimate. They cite several grounds for this assessment. For example, some argue that intuitive judgments are unreliable (Weinberg, Nichols, and Stich 2001; Nichols, Stich, and Weinberg 2003). Likewise, experiments are taken to suggest that they exhibit sensitivity to irrelevant factors (Alexander and Weinberg 2014). It is also suggested that they are not susceptible to systematic error-detection and correction (Weinberg 2007; cf. Swain et al. 2008. See Wright 2010 for a response). Such challenges are general, targeting not just contextualism but the traditional method of cases in general (see Knobe and Nichols 2008; Knobe, Buckwalter, Nichols, et al. 2012; and Deutsch 2015 for helpful opinionated surveys.) But there are also experimental challenges more specific to contextualism to which we now turn.

More in keeping with the "positive program" of experimental philosophy, the contextualists" empirical claim that ordinary linguistic practice with knowledge ascriptions varies with conversational context may be experimentally investigated. Several studies involving presentation of case pairs to non-philosophers failed to find support for a practical factor (stakes) effect (Buckwalter 2010, 2014; May et al. 2010; Feltz \& Zarpentine 2010; and see Pinillos and Simpson 2014 for criticism). Consequently, Schaffer and Knobe raise the following concern:

Strikingly, the results suggest that people simply do not have the intuitions they were purported to have. Looking at this recent evidence, it is easy to come away with the feeling that the whole contextualism debate was founded on a myth. (Schaffer and Knobe 2012: 675).

In reply, contextualists might invoke generic worries about experimental studies, such as worries concerning sampling bias (DeRose 2011). It might also be objected that the linguistic practice involved in producing survey responses is not appropriately representative of ordinary linguistic practice (Cullen 2010; Kauppinen 2007). One way to flesh out this worry is to distinguish withincase knowledge ascriptions (ascriptions made when in an actual case) from about-case knowledge ascriptions (ascriptions made when merely considering a description of a case) (cf. Gerken $M s$ Ch. 2, following Fodor 1964. But see Saxe 2006). The relevant studies may measure about-case judgments, while the contextualist's empirical claim concerns within-case judgments.

Another generic worry about experimental technique concerns survey design. Pinillos and Simpson (2014) suggest that the studies producing null results lacked statistical power. Moreover, the formulations of the prompts used in these studies have been challenged. For instance, DeRose suggests that the details of prompts diverge too much from the best case for contextualism (DeRose 2011 but see Buckwalter 2014). Relatedly, though more broadly, differences in intuitive 
judgments may reflect nothing more than differences in how implicit background details of prompts are "filled in" by respondents (Sosa 2009, 2010). As both contextualists and invariantists have argued, stipulating details of a case is not always sufficient to eliminate this possibility (DeRose 2011; Rysiew 2011; Dinges 2016). Thus, respondents are presented with a non-trivial cognitive task, their completion of which remains opaque to experimenters. The worry, then, is that failure to ensure that participants consider the appropriate questions may threaten the reliability of such surveys.

Subsequent empirical work has begun to address these worries. Concerning the salient alternatives effect, Schaffer and Knobe (2012) presented respondents with prompts including salient alternatives that were more "vivid" (i.e. more salient). Their findings indicate a statistically significant salient alternatives effect on knowledge ascriptions (Buckwalter 2014; Buckwalter and Schaffer 2015). Further evidence for a salient alternatives effect is provided by experimental studies by Nagel and colleagues (Nagel et al. 2013, Nagel 2012). Their results have also been replicated (Alexander et al.2014). Concerning the stakes effect, the picture is murkier. Taken together, various empirical studies (Sripada and Stanley 2012; Hansen and Chemla 2013; Pinillos 2012; Pinillos and Simpson 2014; Shin 2014) provide inconclusive but non-negligible evidence of a practical factor effect on knowledge ascriptions as distinct from a simple stakes effect. Although variance of stakes generates an effect in some studies, there is evidence that it does so due to a connection to action (e.g. Shin 2014; Buckwalter 2014; Buckwalter and Turri forthcoming). This reinforces the impression of a complex practical factor effect that is driven by many moving parts rather than simply by stakes alone.

How does the debate over experimental philosophy reflect upon our two questions? As for Q1, the question as to whether contextualists centrally invoke a distinctive methodology, the debates suggest a negative answer. Some contextualists embrace experimental philosophy and seek to promote contextualism experimentally. For example, Schaffer and Knobe 2012 motivate a contrastivist version of contextualism (Schaffer and Knobe 2012; Gerken and Beebe 2016 provide empirical evidence to the contrary). Other contextualists argue that experimental findings ought to have little impact on the assessment of contextualism (DeRose 2011). Likewise, some invariantists seek to compromise contextualism experimentally or by appeal to findings in psychology (Nagel 2008, 2010; Gerken 2012). But other invariantists are critics of experimental philosophy (Sosa 2007; Brown 2012). So, contextualists and their invariantist opponents do not divide neatly into pro or con about experimental philosophy.

The ramifications of the experimental philosophy debates are less clear for Q2 - the question as to whether disputes about contextualism reflect methodological disputes. A hasty glance at the debates might suggest that experimental philosophers argue against the motivation for contextualism whereas contextualists respond by questioning the significance of experimental work. But even our cursory overview reveals that such an impression is inaccurate. As noted, both contextualists and invariantists use experimental data to argue for and against contextualism, respectively. Likewise, both contextualists and invariantists have questioned whether experimental work should significantly impact epistemological theorizing. Furthermore, there is some apparent methodological common ground between some strands of contextualism and some strands of experimental philosophy - namely, the methodology of the straightforward. Recall that DeRose argues that the intuitive judgments should be prioritized by putting "a very high priority" on making them come out true. In contrast, comparative judgments to the effect that knowledge ascriptions in LOW and HIGH are contradictory should be given "relatively little emphasis" (DeRose 2009. For criticism see Hansen 2014; Gerken Ms). Likewise, proponents of experimental philosophy's negative program appear to sometimes presuppose that laymen's intuitive judgments provide strong reasons to reject conflicting theoretical claims.

In consequence, the debates surrounding experimentalist challenges do not indicate a clear answer to Q2. They clearly raise a number of methodological disputes between contextualists and their opponents but without dividing them along neat methodological lines. 


\section{Concluding remarks}

Let us sum up how the discussion of the various methodological strands bears on our guiding questions, Q1 and Q2.

Q1 is the question as to whether central methodological doctrines are centrally invoked by all epistemic contextualists. We take the diversity of the methodologies surveyed above to suggest that this question should be answered in the negative. For example, the appeal to an imagined genealogy is methodologically very far from arguments from linguistic analogies. Likewise, one might accept an experimental motivation for contextualism and reject the traditional method of cases as methodologically problematic. Consequently, we answer Q1 in the negative: There is no distinctive methodological doctrine or set of methodological doctrines that is centrally invoked by all epistemic contextualists.

Our discussion suggests a more qualified and reserved answer to Q2, the question as to whether dispute about contextualism depends on underlying methodological disputes. In each case, we have seen examples of contextualist and their opponents who argue within a commonly presupposed methodology. On the other hand, we have also seen multiple and prominent examples of methodological differences that lie at the bottom of the first-order dispute. So, on balance we are inclined to answer Q2 in a highly qualified affirmative: The substantive dispute about the truth of contextualism very frequently, although not invariably, reflects an underlying methodological dispute.

This concludes our very selective discussion. Both the first-order debates about contextualism and the meta-epistemological debates about proper methodology are bound to go on. We have sought to exemplify that each of these two levels of debate may benefit from considering it explicitly in relation to the other. Contextualism about "knows" is a fruitful case for metaepistemology. Meta-epistemology may directly inform the first-order debates about the plausibility of contextualism. ${ }^{1}$

\section{Literature}

Alexander, J. Gonnerman, C. and Waterman, J. (2014) "Salience and Epistemic Egocentrism: An Empirical Study" in J. Beebe (ed.) Advances in Experimental Philosophy Continuum, pp. 97-117.

Alexander J and Weinberg JM (2014) 'The "Unreliability" of Epistemic Intuitions' In Machery E and O’Neill E. (eds.) Current Controversies in Experimental Philosophy. New York: Routledge 128145

Bach, K. (2008). Applying Pragmatics to Epistemology, Philosophical Issues, 18: 68-88.

Bach, K. (2010). Knowledge In and Out of Context. In Knowledge and Skepticism (eds. Campbell. J. K., O’Rourke, M. and Silverstein, H.S.) Cambridge, Mass.: MIT Press: 137-163.

Beebe, J. (2012). Social Functions of Knowledge Attributions. In Knowledge Ascriptions (eds. Brown, J. and Gerken, M.) Oxford: Oxford University Press: 220-242.

Blome-Tillmann, M. (2009). Knowledge and Presuppositions. Mind 118 (470): 241-294.

Blome-Tillmann, M. (2012). Presuppositional Epistemic Contextualism and the Problem of Known Presuppositions. In Knowledge Ascriptions (eds. Brown, J. and Gerken, M.), Oxford:

Oxford University Press: 104-119.

Blome-Tillmann, M. (2014). Knowledge and Presuppositions. Oxford University Press.

Brown, J. (2006). Contextualism and Warranted Assertibility Maneuvers. Philosophical Studies, 130: 407-435.

Brown, J. (2012). Words, Concepts and Epistemology. In Knowledge Ascription (eds. Brown, J. and Gerken, M.) Oxford: Oxford University Press: 31-54.

\footnotetext{
${ }^{1}$ The authors contributed equally. Thanks to Daniel Greco and Jonathan Jenkins Ichikawa for helpful comment on previous drafts.
} 
Brown, J. (2013). Experimental Philosophy, Contextualism and SSI. Philosophy and Phenomenological Research 86(2): 233-261.

Brown, J. and Gerken, M. (2012). Knowledge Ascriptions. Oxford University Press.

Buckwalter, W. (2010). Knowledge Isn't Closed on Saturday: A Study in Ordinary Language. Review of Philosophy and Psychology, 1, (3): 395-406.

Buckwalter, W. (2012). Non-Traditional Factors in Judgments about Knowledge. Philosophy Compass 7 (4): 278-289.

Buckwalter, W. (2014). The Mystery of Stakes and Error in Ascriber Intuitions. In (ed. Beebe, J.), Advances in Experimental Epistemology, Bloomsbury: 145-174.

Buckwalter, W. and Schaffer, J. (2015). Knowledge, Stakes, and Mistakes. Nô̂s, 49, (2): 201-234.

Cohen, S. (1999). Contextualism, skepticism, and the structure of reasons. Philosophical Perspectives 13: 57-89.

Cohen, S. (2005). Contextualism Defended, \& Contextualism Defended Some More. In Contemporary Debates in Epistemology (eds. Steup, M. and Sosa, E.). Oxford: Blackwell: 52-62, 6771.

Conee, E. (2005). Contextualism Contested, \& Contextualism Contested Some More. In Contemporary Debates in Epistemology (eds. Steup, M. and Sosa, E.). Oxford: Blackwell: 47-56, 6266.

Craig, E. (1986). The Practical Explication of Knowledge. Proceedings of the Aristotelian Society, 87: 211-26.

Craig, E. (1990). Knowledge and the State of Nature. Oxford: Clarendon Press.

Craig, E. (2007). Genealogies and the state of nature. In Bernard Williams (ed. Thomas, A.). Cambridge University Press: 181-200.

Cullen, S. (2010) Survey-driven romanticism Review of Philosophy and Psychology 1: 275-296

DeRose, K. (1995). Solving the skeptical problem. Philosophical Review 104 (1): 1-52.

DeRose, K. (1999). Contextualism: An Explanation and Defense. In The Blackwell Guide to Epistemology (eds. Greco, J. and Sosa, E.) Oxford: Blackwell: 185-203.

DeRose, K. (2004). Sosa, Safety, Sensitivity, and Skeptical Hypotheses. In Ernest Sosa and His Critics (ed. Greco, J.). Oxford: Blackwell: 22-41.

DeRose, K. (2009). The Case for Contextualism. New York: Oxford University Press.

DeRose, K. (2011). Contextualism, Contrastivism, and X-Phi Surveys. Philosophical Studies 156: 81110.

Deutsch , M. (2015) 'Introduction' In Deutsch M. The Myth of the Intuitive: Experimental Philosophy and Philosophical Method ix-xx. Massachusetts: MIT Press

Dinges, A. (2016). Epistemic invariantism and contextualist intuitions. Episteme 13 (2): 219-232.

Feldman, R. (1999). Contextualism and Skepticism. Philosophical Perspectives 1: Epistemology: 91-114.

Feldman, R. (2001). Skeptical Problems, Contextualist Solutions. Philosophical Studies 103: 61-85. (A revised version of Feldman 1999.)

Feldman, R. (2004). Comments on DeRose's “Single Scoreboard Semantics". Philosophical Studies 119 (1-2): 23-33.

Feltz, A. 2009. Experimental Philosophy. Analyse \& Kritik 31: 201-19.

Fodor, J. (1964). On Knowing What We Would Say. Philosopbical Review, 73 (2): 198-212.

Gelfert, A. (2011). Steps to an Ecology of Knowledge: Continuity and Change in the Genealogy of Knowledge. Episteme 8(1): 67-82.

Gerken, M. (2012). On the Cognitive Bases of Knowledge Ascriptions. In Knowledge Ascriptions, (eds. J. Brown and M. Gerken), Oxford University Press: 140-170.

Gerken, M. (2013). Epistemic Focal Bias. Australasian Journal of Philosophy, Vol. 91, (1): 41-61.

Gerken, M. (2015). The Roles of Knowledge Ascriptions in Epistemic Assessment. European Journal of Philosophy, 23, (1): 141-161.

Gerken, M. (Ms). On Folk. Epistemology.

Gerken, M and Beebe, J. (2016). Knowledge In and Out of Contrast. Noûs 50 (1): 133-164. 
Greco, J. (2007). The Nature of Ability and the Purpose of Knowledge. Philosophical Issues, 17 (1): 57-69.

Greco, J. (2008). What's Wrong With Contextualism? The Philosophical Quarterly 58 (232): 416-436.

Greco, J. (2012). A (Different) Virtue Epistemology. Philosophy and Phenomenological Research, 85, (1): $1-26$.

Hannon, M. (2013). The Practical Origins of Epistemic Contextualism, Erkenntnis, 78 (4): 899919.

Hannon, M. (2015). Stabilizing Knowledge. Pacific Philosophical Quarterly 96, (1): 116-139.

Hansen, N. \& Chemla, E. (2013). Experimenting on Contextualism. Mind and Language 28 (3): 286321.

Hazlett, A. (2009). Knowledge and Conversation. Philosophy and Phenomenological Research 78 (3): 591 620.

Henderson, D. (2009). Motivated Contextualism. Philosophical Studies 142 (1): 119-131.

Henderson, D. (2011). Gate-Keeping Contextualism. Episteme 8 (1): 83-98.

Ichikawa, Jonathan (2011). Quantifiers and epistemic contextualism. Philosophical Studies, 155 (3): 383-398.

Kauppinen, A. (2007) The Rise And Fall Of Experimental Philosophy Philosophical Explorations 10; 2: $95-118$

Kelp, C. (2011). What's the Point of 'Knowledge' Anyway? Episteme, 8, (1): 53-66.

Klein, P. (2000). Contextualism and the Real Nature of Academic Skepticism. Philosophical Issues 10: 108-116.

Klein, P. (2015). Skepticism. The Stanford Encyclopedia of Philosophy (Summer 2015 Edition) (ed. Zalta, E.), URL $=<$ http://plato.stanford.edu/archives/sum2015/entries/skepticism $/>$.

Knobe J. (2007) Experimental Philosophy. Philosophy Compass 2;(1):81-92

Knobe, J., Buckwalter, W., Nichols, S., Robbins, P., Sarkissian, H., and Sommers, T. (2012) Experimental Philosophy. Annual Review of Psychology 63:81-99

Knobe J and Nichols S. (2008) 'An Experimental Philosophy Manifesto' In Experimental Philosophy. Knobe J and Nichols S. (eds.) 3-14. New York: Oxford University Press

Kornblith, H. (2000). The Contextualist Evasion of Epistemology. Nồs 34 (s1):24 - 32.

Kornblith, H. (2011). Why Should We Care About the Concept of Knowledge? Episteme 8(1): 3852.

Kusch, M. (2009). Testimony and the Value of Knowledge. In Epistemic Value (eds. Pritchard, D. Haddock, A. and Millar, A.), Oxford: Oxford University Press: 60-94.

Kusch, M. (2011). Knowledge and Certainties in the Epistemic State of Nature. Episteme, 8 (1): 623.

Lewis, D. (1996). Elusive Knowledge. The Australian Journal of Philosophy, 74: 549-567.

MacFarlane, J. (2014). Assessment Sensitivity: Relative Truth and its Applications. Oxford University Press.

May, J., Sinnot-Armstrong, W., Hull, J.G. \& Zimmerman, A. (2010). Practical Interests, Relevant Alternatives, and Knowledge Attributions: An Empirical Study. Review of Philosophy and Psychology 1 (2): 265-273.

McKenna, R. (2013). 'Knowledge' Ascriptions, Social Roles and Semantics. Episteme 10 (4): 335350.

McKenna, R. (2014). Normative scorekeeping. Synthese 191 (3): 607-625.

Nagel, J. (2008). Knowledge Ascriptions and the Psychological Consequences of Changing Stakes. Australasian Journal of Philosophy, 86: 279-94.

Nagel, J. (2010a). Knowledge Ascriptions and the Psychological Consequences of Thinking about Error. Philosophical Quarterly, 60 (239): 286-306.

Nagel, J. San Juan, V. and Mar, R. (2013). Lay Denial of Knowledge for Justified True Beliefs. Cognition, 129: 652-661. 
Nichols, S., Stich, S. and Weinberg, J. M., (2003) 'Metaskepticism: Meditations in EthnoEpistemology' In Luper, S. (ed.) The Skeptics: Contemporary Essays Aldershot: Ashgate Publishing 227-247

Pinillos, Á. (2012). Knowledge, Experiments, and Practical Interests. In (eds. Brown, J. and Gerken, M.) Knowledge Ascriptions, Oxford University Press: 192-220.

Pinillos, Á. and Simpson, S. (2014). Experimental Evidence Supporting Anti-Intellectualism About Knowledge. In (ed. Beebe. J.) Advances in Experimental Epistemology, Bloomsbury: 9-44.

Pritchard, D. (2010b). Contextualism and Warranted Assertability Maneuvers. In Knowledge and Skepticism (eds. Campbell, J.; O’Rourke, M. and Silverstein, H.). MIT Press: 85-104.

Rysiew, P. (2001). The Context-sensitivity of Knowledge Attributions. Noûs, 35: 477-514.

Rysiew, P. (2011). Surveys, Intuitions, Knowledge Attributions. Philosophical Studies 156(1): 111-120.

Saxe, R. (2006). Why and How to Study Theory of Mind with fMRI. Brain Research, 1079 (1): 5765.

Schaffer, J. and Knobe, J. (2012). Contrastive Knowledge Surveyed. Noûs, 46, (4): 675-708.

Schiffer, S. (1996). Contextualism Solutions to Skepticism. Proceedings of the Aristotelian Society, 96: 317-333.

Schiffer, S. (2004). Skepticism and the Vagaries of Justified Belief. Philosophical Studies, 103: 161-84.

Shin, J. (2014). Time constraints and pragmatic encroachment on knowledge. Episteme 11 (2): 157180.

Sosa, E. (2000). Skepticism and Contextualism. Noûs 34 (s1): 1-18.

Sosa, E. (2007). Experimental Philosophy and Philosophical Intuition. Philosophical Studies, 132 (1): 99-107.

Sosa, E. (2009) 'A Defense of the Use of Intuitions in Philosophy' In Murphy, D., and Bishop, M. (eds.) Stich and His Critics Chichester: Wiley-Blackwell 101-112

Sosa, E. (2010). Intuitions and meaning divergence. Philosophical Psychology, 23 (4): 419-426

Sripada, C. and Stanley, J. (2012). Empirical Tests of Interest-Relative Invariantism. Episteme, 9: 326.

Stanley, J. (2005). Knowledge and Practical Interests. Oxford University Press.

Swain, S., Alexander, J., \& Weinberg, J. (2008). The instability of philosophical intuitions: Running hot and cold on true-temp. Philosophy and Phenomenological Research, 76 (1): 138-155.

Turri, J. (2015b). Skeptical Appeal: The Source-Content Bias. Cognitive Science, 38 (5): 307-324.

Weinberg, J. M. (2007) How to Challenge Intuitions Empirically Without Risking Skepticism. Midwest Studies in Philosopby XXXI; 318-343

Weinberg, J. M., Nichols, S., and Stich, S. (2001) Normativity and Epistemic Intuitions Philosophical Topics 29; 1\&2: 429-460

Wright, Jennifer Cole. (2010). On intuitional stability: The clear, the strong, and the paradigmatic. Cognition, 115, (3): 419-503. 